Slavica

bruxellensia

\section{Slavica bruxellensia}

Revue polyphonique de littérature, culture et histoire

slaves

$1 \mid 2008$

Théâtre

\title{
Zbigniew Herbert, Znaki na papierze
}

\section{Thibault Deleixhe}

\section{OpenEdition \\ Journals}

Édition électronique

URL : http://journals.openedition.org/slavica/242

DOI : $10.4000 /$ slavica.242

ISSN : 2034-6395

Éditeur

Université libre de Bruxelles - ULB

Édition imprimée

Pagination : 70

ISSN : 2031-7654

Référence électronique

Thibault Deleixhe, «Zbigniew Herbert, Znaki na papierze », Slavica bruxellensia [En ligne], 1 | 2008, mis en ligne le 15 octobre 2008, consulté le 22 septembre 2020. URL : http://journals.openedition.org/ slavica/242 ; DOI : https://doi.org/10.4000/slavica.242

Ce document a été généré automatiquement le 22 septembre 2020.

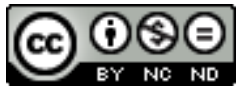

Les contenus de Slavica bruxellensia sont mis à disposition selon les termes de la Licence Creative Commons Attribution - Pas d'Utilisation Commerciale - Pas de Modification 3.0 France. 


\section{Zbigniew Herbert, Znaki na papierze}

Thibault Deleixhe

\section{RÉFÉRENCE}

Zbigniew Herbert, Znaki na papierze (sous la direction de Kulakowska-Lis J.), Olszanica, Bosz, 2008, 180 p. 
Dans une interview, Zbigniew Herbert confiait: «Mon travail préparatoire à un livre, ce sont avant tout des dessins. Je ne fais pas de photos, cela simplifierait mon contact avec l'objet.» Il n'en fallait pas moins pour donner aux éditions Bosz l'envie d'un projet: réunir ces précieuses esquisses de travail et les confronter aux textes qui en sont nés.

Le résultat s'intitule Znaki na papierze (Signes sur papier) et appartient aux objets que l'on est fier de posséder dans sa bibliothèque. Ce livre joliment relié se feuillette avec une étrange légèreté ; l'enchaînement des fragments d'essais, des poèmes brefs et des croquis expressifs $\mathrm{du}$ poète ont des rythmes charmeurs. À

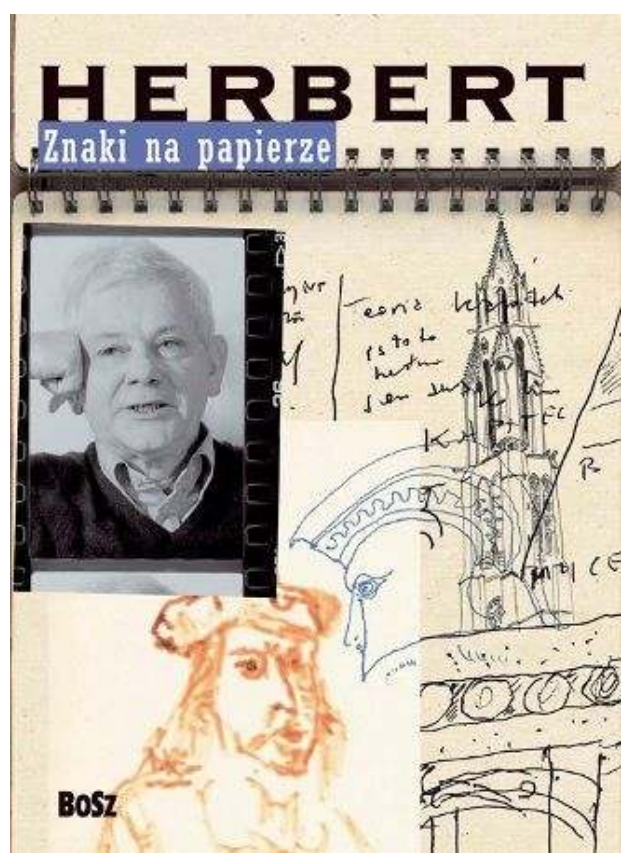
chaque page se retrouve la même volonté de tracer les mystères du monde, à la plume comme au pinceau. Les œuvres présentées y sont décrites ou dépeintes avec énormément de force. Le lecteur est invité à suivre les pas du curateur du grand musée de la culture européenne, une fois dans le cabinet humide d'un grand maître flamand, une autre parmi les secrets de l'Acropole. Les esquisses ne sont pas qu'une simple décoration, ils sont autant d'outils de compréhension des textes et poèmes - souvent très érudits - de l'écrivain. Elles les complètent avec sobriété et informent astucieusement le lecteur non initié à l'histoire de l'art. Bien entendu, le tout est un rien fragmentaire, parfois épars, mais comme le dit l'auteur : " Il n'est de belles villes où l'on ne peut se perdre. » Pourquoi en irait-il autrement avec les livres?

\section{INDEX}

Index géographique : Pologne

Index chronologique : XXe siècle, époque contemporaine

Mots-clés : littérature polonaise

\section{AUTEURS}

\section{THIBAULT DELEIXHE}

Étudiant à l'Université Libre de Bruxelles en Langues et Littératures modernes, orientation slaves 